\title{
Effect of minimal enteral feeding on recovery in a methotrexate-induced gastrointestinal mucositis rat model
}

\author{
Nicoline S. S. Kuiken ${ }^{1,2}$ • Edmond H. H. M. Rings ${ }^{3,4}$ • Rick Havinga ${ }^{2}$ - Albert K. Groen ${ }^{2}$ • \\ Wim J. E Tissing ${ }^{1}$
}

Received: 21 April 2015 / Accepted: 16 August 2015 /Published online: 3 September 2015

(C) The Author(s) 2015. This article is published with open access at Springerlink.com

\begin{abstract}
Purpose Patients suffering from gastrointestinal mucositis often receive parenteral nutrition as nutritional support. However, the absence of enteral nutrition might not be beneficial for the intestine. We aimed to determine the feasibility of minimal enteral feeding (MEF) administration in a methotrexate (MTX)-induced mucositis rat model and thereby determine the effect of MEF on recovery.

Methods Male Wistar rats were attached to swivel systems from day 1 to 5 after $45 \mathrm{mg} / \mathrm{kg}$ MTX IV injection. The MTX group continued ad libitum feeding, and the MTX+ MEF group continued ad libitum feeding and received from day 1 to 5 continuously MEF. MEF consisted of $20 \%$ of their normal caloric intake. We measured body weight, intake, and plasma citrulline. At day 10, the rats were terminated and villus and crypt length were measured.

Results The administration of MEF caused no increased severity of mucositis phenotype, with comparable caloric intake, body weight, and plasma citrulline during mucositis. The recovery of plasma citrulline levels was not different between
\end{abstract}

Wim J. E Tissing

w.j.e.tissing@umcg.nl

1 Department of Pediatric Oncology, Beatrix Children's Hospital, University of Groningen, University Medical Center Groningen, Groningen, The Netherlands

2 Department of Pediatric Gastroenterology and Hepatology, Beatrix Children's Hospital, University of Groningen, University Medical Center Groningen, PO Box 30001, 9700

RB Groningen, The Netherlands

3 Department of Pediatrics, Leiden University Medical Center, Leiden University, Leiden, The Netherlands

4 Department of Pediatrics, Erasmus Medical Center Rotterdam, Erasmus University Rotterdam, Rotterdam, The Netherlands both groups. At day 7 and 8 , the MTX + MEF group gained significantly more weight ( $p<0.05$ and $p<0.01$, respectively), and at day 8 and 9 the total caloric intake was significantly increased $(p<0.01$ and $p<0.05$, respectively) compared to the MTX group. At day 10, the rats from the MTX+MEF group showed a significant increase in jejunal villus length compared to the MTX group $(p<0.05)$.

Conclusions This is the first study in which the feasibility of MEF administration during chemotherapy-induced mucositis was determined. This study indicates that MEF administration is feasible during mucositis and suggests that MEF accelerates recovery after MTX-induced mucositis.

Keywords Gastrointestinal mucositis - Minimal enteral feeding $\cdot$ Nutrition $\cdot$ Chemotherapy $\cdot$ Methotrexate $\cdot$

Citrulline $\cdot$ Rat

\section{Introduction}

Gastrointestinal mucositis, further referred to as mucositis, is a severe side effect of chemotherapy and radiotherapy [1]. Mucositis is a common clinical problem with an estimated incidence of $40-100 \%$ of patients with chemotherapy [2]. The incidence is particularly high in children with acute myeloid leukemia, B-non-Hodgkin lymphoma, and after autologous and allogeneic stem cell transplantation, due to the high dosage of chemotherapy. Mucositis is a mechanism of different biological stages resulting in villus atrophy, ulceration, and loss of barrier function, ending with spontaneous healing [1-3]. Patients suffer from nausea, vomiting, diarrhea, pain, and weight loss, and are at an increased risk of sepsis or bacteremia $[1,2,4]$. The consequences of mucositis limit the ability to tolerate chemotherapy and therefore cause a reduction of doses of chemotherapy or cause a delay of the next 
chemotherapy cycle, which eventually affects the patient survival [2].

An optimal feeding strategy during mucositis might improve the nutritional state and thereby increase survival, but until now there is no rational feeding strategy. In previous animal studies, we have shown that amino acids and glucose were only absorbed if continuously enterally administered [5-7]. However, fatty acids and lactose were not digested and absorbed even if continuously enterally administered $[5,8]$. We concluded that administration of total enteral tube feeding is not feasible in the rat, and for the rat the parenteral feeding regimen is superior to maintain body weight, compared to the enteral regimen [9]. However, total parenteral nutrition has disadvantages. In animal models of other intestinal diseases, it has been shown that total parenteral nutrition induces apoptosis, villus atrophy, and mucosal permeability, probably due to the lack of enteral nutrition [10-13]. This might be even more disadvantageous in patients already experiencing mucositis.

The disadvantages of the lack of trophic effects might be overcome by minimal enteral feeding (MEF), a small amount of elementary nutrition administered as continuous tube feeding. MEF has been shown to have a positive effect on intestinal growth, enterocyte function, and maintenance of barrier function in animal models concerning other intestinal diseases, and has often been used in the premature infant [14-17]. However, there are no data on the use of MEF during mucositis.

MEF could be an intervention to accelerate the regeneration of the damaged intestinal mucosa after chemotherapy and consequently speed up recovery to overcome the lack of trophic effects during treatment with total parental nutrition. Therefore, we chose to determine the feasibility of MEF administration during mucositis in a methotrexate (MTX)-induced intestinal mucositis rat model and thereby determine the effect of MEF on recovery.

\section{Methods}

\section{Animals and housing}

Male Wistar outbred rats (4 weeks old, 85-95 g) were obtained from Charles River (Sulzfeld, Germany). They were housed in individual Plexiglas cages under controlled temperature and humidity, and a $12-12 \mathrm{~h}$ lightdark cycle (7.00 AM-7.00 PM). AIN93G diet $[5,18]$ and water were available ad libitum. The study protocol was approved by the Ethics committee for Animal experiments, Faculty of Medical Sciences, University of Groningen, The Netherlands.

\section{Materials}

Methotrexate was obtained from Pharmachemie Holding B.V. (Haarlem, the Netherlands). Purified diet, AIN93G, was obtained from Research Diet Services (Wijk bij Duurstede, the Netherlands). Tube feeding Neocate ${ }^{\circledR}$ Advance was purchased from Nutricia (Zoetermeer, the Netherlands).

\section{Experimental methods}

Rats had surgery 1 week after arrival at the age of 5-6 weeks. They received a permanent catheter in the duodenum which was subcutaneously tunneled to the head, where attachment to the swivel system was possible, as done before [9]. All rats were allowed to recover 1 week. At day 0 , at an age of 6-7 weeks, the rats (199-221 g) received MTX $45 \mathrm{mg} / \mathrm{kg}$ $(n=14)$ or $\mathrm{NaCl} 0.9 \%(n=2)$ intravenously (iv) in the dorsal penile vein under general anesthesia. In a pilot experiment, the previous validated dose of $60 \mathrm{mg} / \mathrm{kg}$ MTX induced too much toxicity in the rats in this experimental design (data not shown). Therefore, the dose of MTX was lowered from 60 to $45 \mathrm{mg} / \mathrm{kg}$. After the MTX/NaCl injection, all rats were attached to swivels in a cage with filter top, a swivel joint and counterbalance system from day 1 till day 5 , as done before $[9,19]$. From day 5 till day 10, all rats were in their regular Plexiglas cages unattached from the swivels. Daily food intake and body weight were measured, and diarrhea, pica (= ingestion of non-food substances as sign of emesis $[20,21])$, and illness (bad fur, red nose, or decreased activity) were scored as yes/no. Every 2 days, the severity of mucositis was objectified by measuring plasma citrulline levels in blood samples from the tail tip $(70 \mu \mathrm{l})$. Plasma citrulline represents functional enterocyte mass and is a marker of mucositis [22-26]. At day 10, all rats were euthanized under general anesthesia by obtaining a large blood sample through vena cava inferior puncture, followed by cervical dislocation. Blood samples were centrifuged for $10 \mathrm{~min}$ at $2000 \times \mathrm{g}$ and collected plasma was stored at $-20{ }^{\circ} \mathrm{C}$ until further analysis. The abdomen was opened and the small intestine excised, and flushed with PBS. Smaller parts for jejunal histology $(1 \mathrm{~cm})$ were fixed in formalin, dehydrated, and embedded in paraffin according to standard procedures for histology.

\section{Feeding strategies}

All three groups continued AIN93G ad libitum during the complete experiment because a forced food restriction of $80 \%$ for 4 days in the MTX+MEF group was regarded to be not ethical. Controls $(n=2)$ received $\mathrm{NaCl} 0.9 \%$ iv to show the normal intake and growth when attached to a swivel system. Only two control rats were used since we have used this model many times, and control rats have performed similarly over all 
studies [5-9]. All other rats were randomly divided into two groups. The MTX group $(n=7)$ received MTX $45 \mathrm{mg} / \mathrm{kg}$ iv. The MTX+MEF group $(n=7)$ received MTX $45 \mathrm{mg} / \mathrm{kg}$ iv and received from day 1 to 5 forced continuous minimal enteral tube feeding containing $20 \%$ of the normal total caloric intake. This amount of tube feeding was based on the use of MEF in animal studies in other intestinal diseases [13, 15, 16]. From our previous studies, we know that saline-treated control rats eat about an average of $329 \mathrm{kcal} / \mathrm{kg} /$ day of AIN93G $[5,9,18]$. The caloric intake was daily adapted to the body weight, $66 \mathrm{kcal} / \mathrm{kg} / \mathrm{day}$, and the enteral tube feeding was prepared twice daily. The enteral tube feeding used in this study was Neocate ${ }^{\circledR}$ Advance, which is the most elementary diet available in clinical practice at the moment. In Table 1, the feeding strategies with distribution of calories via enteral tube are summarized, and in Table 2 the energy distribution and composition of both diets are summarized.

\section{Analytical methods}

\section{Histology}

Hematoxylin and eosin staining (H\&E) was done on $3-\mu m$-thick sections of formalin-fixed jejunal segments to assess histology. Morphometric analysis was performed as described previously [5, 27]. The H\&E slides were scanned using the Aperio Scanscope (Aperio Technologies, Vista, CA, USA). Villus and crypt length were measured manually in well-orientated sections (ten measurements per rat) from digitized images that were evaluated at $\times 10$ magnification by using Aperio Imagescope software (Aperio Technologies).

\section{Plasma citrulline concentration}

In $30 \mu \mathrm{l}$ plasma $(=70 \mu \mathrm{l}$ blood $)$ at room temperature, the plasma citrulline concentration was measured by using automated ion exchange column chromatography, as described before $[5,28,29]$.

\section{Statistical analysis}

Statistical analysis was done by using SPSS version 22.0 for Windows (SPSS Inc., Chicago, IL, USA). The values are expressed as medians and ranges in text, or interquartile ranges in figures. The two control rats were not included in the statistical analysis. Data analysis between the MTX and MTX+MEF group was performed by using a Mann-Whitney $U$ test. A $p$ value $<0.05$ was considered statistically significant.

\section{Results}

\section{MEF in the mucositis rat model}

We determined the feasibility of MEF administration during mucositis and the effect of MEF on recovery. All rats tolerated the MTX $45 \mathrm{mg} / \mathrm{kg}$ and tolerated the administration of MEF during four consecutive days via attachment to the swivel system. One rat from the MTX group had to be terminated on day 9 due to too much weight loss and illness. One rat from the MTX+MEF group died shortly after start of the tube feeding, due to a problem with the duodenal catheter, and was therefore excluded from analysis. All rats from both MTX groups developed a mucositis phenotype, with decreased food intake and less growth, as described below. Other features of the mucositis phenotype were illness (bad fur, red nose, or

Table 1 Feeding strategies

\begin{tabular}{llll}
\hline & $\begin{array}{l}\text { Controls } \\
\text { NaCl } 0.9 \%(n=2)\end{array}$ & $\begin{array}{l}\text { MTX group } \\
\text { MTX }(n=7)\end{array}$ & $\begin{array}{l}\text { MTX+MEF group } \\
\text { MTX }(n=6-7)^{\mathrm{a}}\end{array}$ \\
\hline $\begin{array}{lll}\text { Feeding strategy } \\
\text { Diet ad libitum (kcal) }\end{array}$ & Ad libitum & Ad libitum & MEF+ad libitum \\
$\quad$ Amount & AIN93G $(3.76 \mathrm{kcal} / \mathrm{g})$ & AIN93G $(3.76 \mathrm{kcal} / \mathrm{g})$ & AIN93G $(3.76 \mathrm{kcal} / \mathrm{g})$ \\
Tube feeding & Ad libitum & Ad libitum & Ad libitum \\
Diet for tube feeding $(\mathrm{kcal} / \mathrm{kg})$ & - & - & $20 \%$ of normal kcal intake= MEF \\
& - & - & Neocate \\
& & & $(4000 \mathrm{kcal} / \mathrm{kg})$ \\
$\quad$ Amounce
\end{tabular}

MTX methotrexate, MEF minimal enteral feeding

${ }^{a}$ One rat died shortly after start of the tube feeding and was therefore excluded from analysis

${ }^{\mathrm{b}}$ Average normal kcal intake known from previous experiments is about $329 \mathrm{kcal} / \mathrm{kg} / \mathrm{day}$ [5, 9, 18] 
Table 2 Energy distribution and composition of diet

\begin{tabular}{|c|c|c|}
\hline & Neocate $^{(B)}$ Advance & AIN93G [18] \\
\hline \multirow[t]{2}{*}{ Kcal } & $4000 \mathrm{kcal} / \mathrm{kg}$ & $3760 \mathrm{kcal} / \mathrm{kg}$ \\
\hline & \multicolumn{2}{|l|}{ Energy distribution } \\
\hline Proteins & $10 \%$ & $19 \%$ \\
\hline Carbohydrates & $59 \%$ & $64 \%$ \\
\hline \multirow[t]{2}{*}{ Fats } & $31 \%$ & $17 \%$ \\
\hline & \multicolumn{2}{|c|}{ Composition of diets, per $\mathrm{kg}$ diet } \\
\hline Protein equivalent $(\mathrm{g})$ & 100 & a \\
\hline Free amino acids (g) & 120 & a \\
\hline Casein $(\mathrm{g})$ & - & 200 \\
\hline L-Cystine (g) & - & 3 \\
\hline Carbohydrate & $585 \mathrm{~g}$ & \\
\hline Cornstarch (g) & - & 529.5 \\
\hline Glucose (g) & 12 & - \\
\hline Maltose (g) & 41 & - \\
\hline Maltotriose (g) & 59 & - \\
\hline Sucrose $(g)$ & - & 100 \\
\hline Lactose (g) & - & - \\
\hline Polysaccharides (g) & 473 & 50 \\
\hline Fat & $140 \mathrm{~g}$ & 70 g soybean oil \\
\hline Saturated (g) & 53 & 10.8 \\
\hline $\mathrm{MCT}(\mathrm{g})$ & 47 & - \\
\hline Monounsaturated (g) & 61 & 16.3 \\
\hline Polyunsaturated (g) & 19 & 40.5 \\
\hline - Linoleic acid (g) & 16 & 35.7 \\
\hline - Linolenic acid (g) & 3 & 4.8 \\
\hline Minerals & & $35 \mathrm{~g} / \mathrm{kg}$ mineral mix \\
\hline Sodium (mg) & 2400 & 1019 \\
\hline Potassium (mg) & 4680 & 3600 \\
\hline Chloride (mg) & 3680 & 1571 \\
\hline Calcium (mg) & 2000 & 5000 \\
\hline Phosphorus (mg) & 1560 & 1561 \\
\hline Magnesium (mg) & 500 & 507 \\
\hline Iron (mg) & 24.8 & 35 \\
\hline Zinc (mg) & 20 & 38 \\
\hline Copper (mg) & 2.4 & 6.0 \\
\hline Manganese (mg) & 20 & 10 \\
\hline Molybdenum (mg) & 0.14 & 0.15 \\
\hline Selenium (mg) & 0.1 & 0.15 \\
\hline Chromium (mg) & 0.05 & 1.0 \\
\hline Iodine (mg) & 0.28 & 0.2 \\
\hline Silicon (mg) & - & 5.0 \\
\hline Nickel (mg) & - & 0.5 \\
\hline Boron (mg) & - & 0.5 \\
\hline Lithium (mg) & - & 0.1 \\
\hline Vanadium (mg) & - & 0.1 \\
\hline Fluoride (mg) & - & 1.0 \\
\hline
\end{tabular}

Table 2 (continued)

\begin{tabular}{lll}
\hline & Neocate $^{\circledR}$ Advance & AIN93G [18] \\
\hline Vitamins & & $10 \mathrm{~g} / \mathrm{kg}$ vitamin mix \\
Vitamin A & $1480 \mu \mathrm{g} \mathrm{RE}$ & $4000 \mathrm{IU}$ \\
$\quad-$ Carotenoids & - & - \\
Vitamin D & $32.4 \mu \mathrm{g}$ & $1000 \mathrm{IU}$ \\
Vitamin E & $23.2 \mathrm{mg} \alpha$-TE & $75 \mathrm{IU}$ \\
Vitamin K ( $\mu \mathrm{g})$ & 140 & 750 \\
Thiamin $(\mathrm{mg})$ & 2.4 & 5 \\
Riboflavin $(\mathrm{mg})$ & 3.2 & 6 \\
Niacin & $72 \mathrm{mg} \mathrm{NE}$ & - \\
Pantothenic acid $(\mathrm{mg})$ & 10 & 15 \\
Vitamin $\mathrm{B}_{6}(\mathrm{mg})$ & 3.2 & - \\
Folic acid $(\mathrm{mg})$ & 0.4 & 2 \\
Vitamin $\mathrm{B}_{12}(\mu \mathrm{g})$ & 2.8 & 25 \\
Biotin $(\mu \mathrm{g})$ & 80 & 200 \\
Vitamin C $(\mathrm{mg})$ & 132 & - \\
Others & & - \\
Carnitine $(\mathrm{mg})$ & 100 & - \\
Choline $(\mathrm{mg})$ & 768 & 1000 \\
Taurine $(\mathrm{mg})$ & 200 & - \\
\hline
\end{tabular}

$M C T$ medium chain triglycerides

${ }^{a}$ Exact amount of protein equivalent and exact amount of free amino acids in casein are unavailable. Casein and L-cystine are the sole source of protein in AIN93G diet

decreased activity), pica, and diarrhea, which did not differ between both MTX groups (data not shown).

\section{Intake}

The food intake of both MTX groups decreased during the days of mucositis, day $1-5$. At day 3 , the median AIN93G food intake in grams in the MTX + MEF group was significantly lower compared to the MTX group (3.5, 0-7, and 12, $3-13$, respectively; $p<0.05$ ).

Figure 1a shows the total energy intake in calories, which is a combination of the food intake and MEF. All rats from the MTX+MEF group received daily $20 \%$ of their calculated normal caloric intake via tube feeding, during day 1 till day 5. The total caloric intake was comparable in the MTX+ MEF group and MTX group during mucositis. However, during the recovery phase, on day 8 and 9 , the MTX + MEF group had a significantly higher total caloric intake compared to the MTX group ( $p<0.01$ and $p<0.05$, respectively).

\section{Body weight}

Figure $1 \mathrm{~b}$ shows the weight gain over time in grams per day. Figure $1 \mathrm{c}$ shows the body weight from day 0 till day 10 . At day 0 , before MTX injection, the body weight in all groups was 


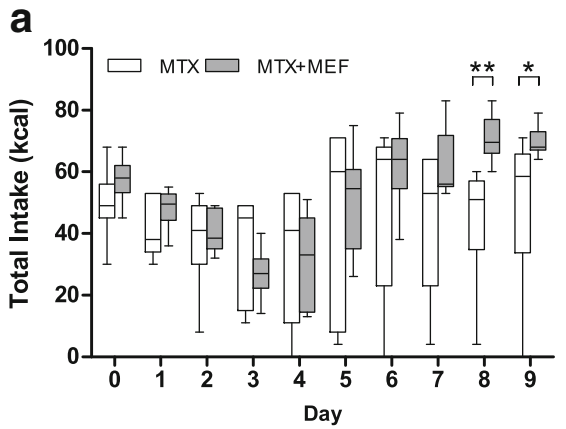

Fig. 1 Intake and body weight. Total intake (a), body weight gain per day (b), and body weight over time (c) in methotrexate (MTX)-treated rats. In MTX group, total intake consists of the AIN93G food intake. In the MTX+minimal enteral feeding (MEF) group, total intake consists of AIN93G food intake combined with MEF. MTX iv injection at day 0. MEF was administered from day 1 to 5 in the MTX + MEF group. Data

comparable. For both MTX groups, the body weight stabilized or the rats lost weight during the first days of mucositis. In the recovery phase (day 5-10), both MTX groups regained growth and increased weight from day 5 after MTX. However, at day 7 and day 8 , the weight gain of the MTX + MEF group was significantly higher compared to the MTX group ( $p<0.05$ and $p<0.01$, respectively). At day 10, the body weight of the MTX $+\mathrm{MEF}$ group tended to be higher compared to the MTX group ( $p=0.08)$.

\section{Plasma citrulline}

Figure 2 shows the plasma citrulline levels from day 0 till day 10. The plasma citrulline levels decreased to the lowest level at day 4 in both the MTX group and MTX + MEF group. The plasma citrulline level at day 10 was not different between the MTX and MTX+MEF group $(p=0.15)$.

\section{Histology}

Figure 3 shows the villus length and crypt length at day 10 with a histological example of both MTX and MTX+MEF in Fig. 4. At day 10 , the rats from the MTX+MEF group showed a

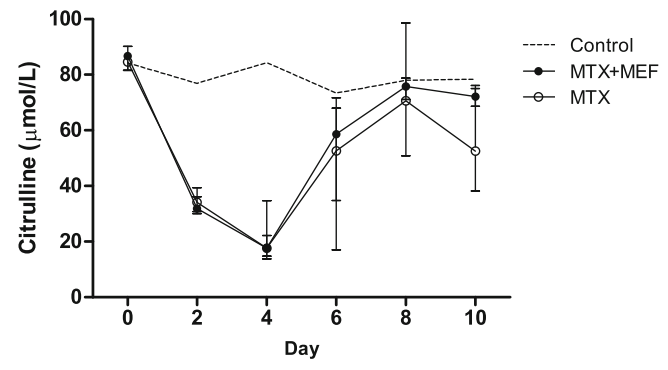

Fig. 2 Plasma citrulline. Citrulline ( $\mu \mathrm{mol} / \mathrm{l})$ measured every 2 days. Data represent medians and interquartile ranges. Methotrexate (MTX) iv injection at day 0 . Minimal enteral feeding (MEF) was administered from day 1 to 5 . MTX+MEF $(n=6)$ and $\operatorname{MTX}(n=7 ; n=6$ at day 10 because one rat had to be terminated at day 9). The dashed line shows the median of the controls

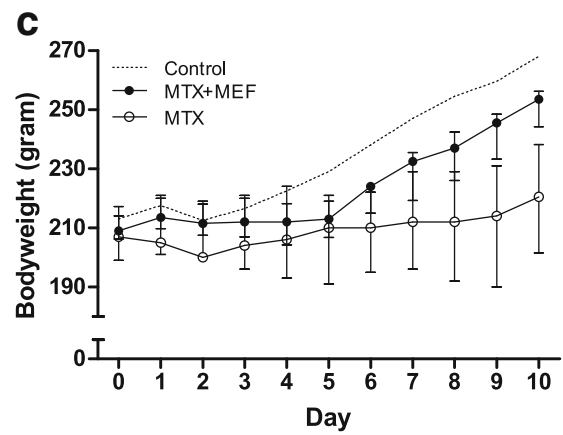

represent medians and interquartile ranges $(\mathbf{a}-\mathbf{c})$. a, b $\operatorname{MTX}(n=7 ; n=6$ at day 9 because one rat had to be terminated at day 9), MTX+MEF $(n=6)$. ${ }^{*} p<0.05$ and ${ }^{* *} p<0.01$ MTX versus MTX+MEF. $\mathbf{c} \operatorname{MTX}(n=7 ; n=6$ at day 10 because one rat had to be terminated at day 9), MTX+MEF $(n=6)$. The dashed line shows the median of the controls

significantly higher villus length in the jejunum compared to the MTX group $(p<0.05)$, a comparable length as controls ( $577 \mu \mathrm{m}$, 530-624). The crypt length in the jejunum was comparable in both groups, a comparable length as controls $(188 \mu \mathrm{m}, 179-198)$.

\section{Discussion}

This is the first study in which the feasibility of MEF administration during chemotherapy-induced mucositis was determined. Our data indicate that the administration of MEF during mucositis is feasible, that MEF does not increase morbidity due to mucositis, and even more, it suggests that MEF accelerates recovery in a previously established MTXinduced mucositis rat model.

First, we determined the feasibility of MEF administration during MTX-induced mucositis. The effects of MTX on induction of mucositis became apparent in the clinical parameters during the first four days after MTX administration. The body weight of the rats stabilized, as opposed to controls which continued to grow, and the food intake decreased during mucositis in both MTX groups. The development of
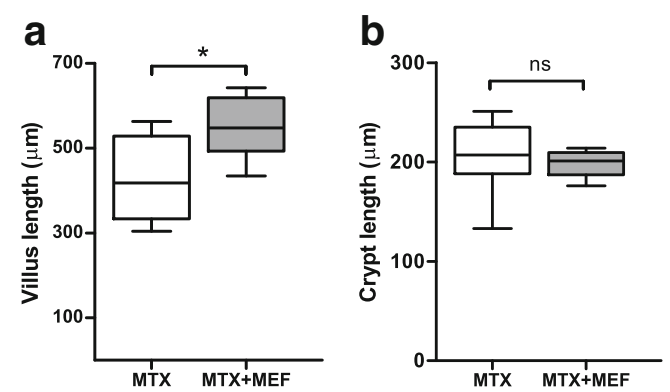

Fig. 3 Villus and crypt length. Jejunal villus length at day 10 (a). Jejunal crypt length at day $10(\mathbf{b})$. Data represent medians and interquartile ranges $(n=6-7)$. Measurements in one rat in the methotrexate (MTX) group performed at day $9 .{ }^{*} p<0.05 \mathrm{MTX}+$ minimal enteral feeding (MEF) versus MTX. $n s$ not significant 
Fig. 4 Histology of jejunum. Hematoxylin and eosin (H\&E) staining showing morphology at day 10. Bars represent $300 \mu \mathrm{m}$. a Methotrexate (MTX) rat. b MTX + minimal enteral feeding (MEF) rat
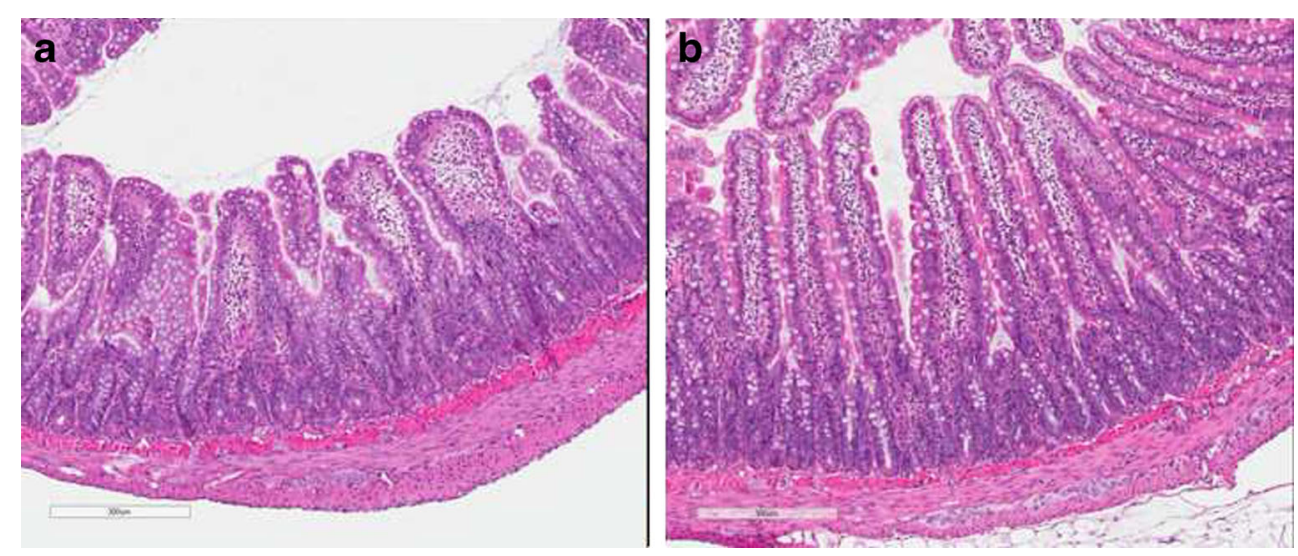

mucositis was comparable with our previous studies, with the lowest level of plasma citrulline (a marker of functional enterocyte mass) at day 4 [5-9]. MEF caused no altered functional enterocyte mass compared with MTX group. Furthermore, the administration of MEF caused no increased severity of mucositis phenotype, with comparable caloric intake and body weight during mucositis. Therefore, the results show that it is feasible to administer MEF during four consecutive days in this MTX-induced mucositis rat model.

Further, after the feasibility of MEF administration during mucositis, we determined the effect of MEF on the recovery after mucositis. First, the clinical parameters showed a significant higher food intake and weight gain after mucositis. Although the difference in body weight between both groups at day 10 only tended to be higher, our results suggest a trend for a faster recovery of body weight gain due to MEF. Second, in the recovery phase, citrulline levels reached their normal levels again, although there was no significant difference in the citrulline levels between both groups. Finally, we determined the intestinal damage by histology at termination, with the measurement of villus length and crypt length 10 days after MTX. The crypts were completely recovered regardless of MEF on day 10 and are comparable to the crypt length of controls. This was as expected since we know from previous studies that crypts regenerate rapidly and prior to the recovery of villus atrophy, with even crypt hyperplasia shown at $96 \mathrm{~h}$ after MTX injection [5, 30]. However, the villus length was significantly longer in the MTX + MEF group, comparable to controls in this study and to the villus length determined at several time points in a previous study [30]. Therefore, this indicates a faster recovery of villus atrophy. In conclusion, the data suggest that MEF administration might accelerate recovery after mucositis, with a faster recovery of villus atrophy in combination with faster recovery of clinical parameters like intake and body weight gain.

To our knowledge, this is the first study that determined the feasibility and effect of MEF administration continuously during mucositis. Therefore, we cannot compare our results directly to other performed experiments. However, our results agree with studies performed in animal models of other intestinal diseases, concluding that MEF stimulates the intestine with an increase in jejunal villus length [14-16]. It should be noted that we did not compare different percentages of MEF; therefore, the optimal amount of MEF necessary for a faster recovery after mucositis was not established in this study. The percentage we used was comparable to the percentage tolerated in clinical practice and comparable to percentages in animal studies of other intestinal diseases in which MEF has been shown to be feasible and effective $[15,16]$.

In contrast to other studies, we did not administer parenteral nutrition in combination with MEF [14-16]. We chose for this protocol since we wanted to determine the feasibility of MEF administration reflected in parameters like body weight and intake, which would be confounded by simultaneous parenteral nutrition.

Interestingly, administration of MEF reduced food intake of the rats, although total caloric intake remained the similar. The differences between both groups are the composition of both diets and the timing of the intake. The MEF is a continuous supplied elementary diet, and thus most of the nutrients do not have to be digested before absorption. Moreover, the normal food intake of the rats takes place in boluses, whereas we know that this bolus feeding is not effectively absorbed during mucositis [5-8]. Therefore, the continuous intestinal stimulation with elementary nutrients is not only feasible during mucositis but it may cause even a faster recovery, as shown in a faster recovery of intake, body weight gain, and villus length. Since the AIN93G diet probably also has trophic effects on the gut, the cause of this faster recovery remains unclear.

There are some limitations to this study. First, we did not compare MEF only versus ad libitum intake because a forced food restriction of $80 \%$ for 4 days was regarded to be not ethical. However, in our opinion this study design, MEF + ad libitum versus ad libitum, was still sufficient to answer the primary objective. Second, in patients the effect of chemotherapy on the intestine probably happens less fast and the recovery phase is longer [2]. Therefore, our model does not 
completely fit into clinical practice, although we do believe that this does not make our results less likely to be useful in the human setting. Third, the body weight in pediatric patients logically does not increase as fast as in rats. However, we chose these young rats to see the feasibility and effect of MEF administration in the very short recovery phase. Therefore, we speculate that the advantage of MEF administration might be even more pronounced in patients due to the longer recovery phase. Finally, we did not determine the intestinal function during and after mucositis. Therefore, we cannot draw any conclusions about recovery of the intestinal function.

In clinical practice, the optimal feeding strategy during mucositis is unknown. Patients are often unable to tolerate enteral nutrition and therefore often receive parenteral nutrition as nutritional support. However, the absence of enteral nutrition might not be beneficial for the intestine. In this study, we showed that MEF administration is feasible during mucositis and moreover our data suggest that MEF accelerates recovery. Therefore, MEF might be a good option to overcome the effects on the gut due to the lack of enteral nutrition. Furthermore, we speculate that MEF might have a positive effect on recovery, allowing the patient to either receive a higher dose of chemotherapy or to start the next chemotherapy course according to the protocol without any delay, which eventually might influence the survival.

The results of our study warrant the much more technically difficult study of TPN versus TPN +MEF and future studies in humans on the use of MEF in patients with mucositis, to determine the beneficial effects of the additive of MEF to parenteral nutrition, and to understand the mechanism of action.

In summary, this is the first study that determined the feasibility of MEF administration during mucositis and the effect of MEF on the recovery after mucositis. The administration of MEF causes no increased severity of the mucositis phenotype and is therefore feasible during mucositis. Even more, in the MTX+MEF group, the intake and body weight gain were significantly higher in the recovery phase. Moreover, the villus length was significantly longer 10 days after MTX. Therefore, our data suggest that MEF speeds up the recovery after mucositis in the rat. The effect of MEF may be even more pronounced in patients due to a longer recovery phase in comparison to the rat. If a patient receives parenteral nutrition, MEF might be a good option to overcome the lack of enteral nutrition.

Acknowledgment The authors wish to thank Angelika Jurdzinski for technical assistance in our studies.

Grants This study was financially supported by the Dutch Cancer Society (grant number 5272).
Conflict of Interest The authors declare that they have no conflict of interest. All authors have full control of all primary data and agree to allow the journal to review the data if requested.

Open Access This article is distributed under the terms of the Creative Commons Attribution-NonCommercial 4.0 International License (http:// creativecommons.org/licenses/by-nc/4.0/), which permits any noncommercial use, distribution, and reproduction in any medium, provided you give appropriate credit to the original author(s) and the source, provide a link to the Creative Commons license, and indicate if changes were made.

\section{References}

1. Sonis ST (2004) The pathobiology of mucositis. Nat Rev Cancer 4: 277-284

2. Sonis ST, Elting LS, Keefe D, Peterson DE, Schubert M, HauerJensen M, Bekele BN, Raber-Durlacher J, Donnelly JP, Rubenstein EB, Mucositis Study Section of the Multinational Association for Supportive Care in Cancer, International Society for Oral Oncology (2004) Perspectives on cancer therapy-induced mucosal injury: pathogenesis, measurement, epidemiology, and consequences for patients. Cancer 100:1995-2025

3. Rubenstein EB, Peterson DE, Schubert M, Keefe D, McGuire D, Epstein J, Elting LS, Fox PC, Cooksley C, Sonis ST, Mucositis Study Section of the Multinational Association for Supportive Care in Cancer, International Society for Oral Oncology (2004) Clinical practice guidelines for the prevention and treatment of cancer therapy-induced oral and gastrointestinal mucositis. Cancer 100:2026-2046

4. Keefe DM, Schubert MM, Elting LS, Sonis ST, Epstein JB, RaberDurlacher JE, Migliorati CA, McGuire DB, Hutchins RD, Peterson DE, Mucositis Study Section of the Multinational Association of Supportive Care in Cancer and the International Society for Oral Oncology (2007) Updated clinical practice guidelines for the prevention and treatment of mucositis. Cancer 109:820-831

5. Fijlstra M, Rings EH, Verkade HJ, van Dijk TH, Kamps WA, Tissing WJ (2011) Lactose maldigestion during methotrexateinduced gastrointestinal mucositis in a rat model. Am J Physiol Gastrointest Liver Physiol 300:G283-G291

6. Fijlstra M, Rings EH, van Dijk TH, Plosch T, Verkade HJ, Tissing WJ (2013) Continuous enteral administration can overcome the limited capacity to absorb glucose in rats with methotrexateinduced gastrointestinal mucositis. Support Care Cancer 21:863871

7. Fijlstra M, Schierbeek H, Voortman G, Dorst KY, van Goudoever JB, Rings EH, Tissing WJ (2012) Continuous enteral administration can enable normal amino acid absorption in rats with methotrexate-induced gastrointestinal mucositis. J Nutr 142:19831990

8. Fijlstra M, Tissing WJ, Stellaard F, Verkade HJ, Rings EH (2013) Reduced absorption of long-chain fatty acids during methotrexateinduced gastrointestinal mucositis in the rat. Clin Nutr 32:452-459

9. Fijlstra M, Tissing WJE, Verkade HJ, Rings EHHM (2013) Parenteral feeding during methotrexate-induced gastrointestinal mucositis prevents weight loss in the rat 8:e95-e99

10. Sun X, Spencer AU, Yang H, Haxhija EQ, Teitelbaum DH (2006) Impact of caloric intake on parenteral nutrition-associated intestinal morphology and mucosal barrier function. JPEN J Parenter Enteral Nutr 30:474-479

11. Feng Y, Ralls MW, Xiao W, Miyasaka E, Herman RS, Teitelbaum DH (2012) Loss of enteral nutrition in a mouse model results in 
intestinal epithelial barrier dysfunction. Ann N Y Acad Sci 1258: 71-77

12. Yang H, Feng Y, Sun X, Teitelbaum DH (2009) Enteral versus parenteral nutrition: effect on intestinal barrier function. Ann N Y Acad Sci 1165:338-346

13. Wildhaber BE, Yang H, Spencer AU, Drongowski RA, Teitelbaum DH (2005) Lack of enteral nutrition - effects on the intestinal immune system. J Surg Res 123:8-16

14. Burrin DG, Stoll B, Jiang R, Chang X, Hartmann B, Holst JJ, Greeley GH Jr, Reeds PJ (2000) Minimal enteral nutrient requirements for intestinal growth in neonatal piglets: how much is enough? Am J Clin Nutr 71:1603-1610

15. Ohta K, Omura K, Hirano K, Kanehira E, Ishikawa N, Kato Y, Kawakami K, Watanabe G (2003) The effects of an additive small amount of a low residual diet against total parenteral nutritioninduced gut mucosal barrier. Am J Surg 185:79-85

16. Omura K, Hirano K, Kanehira E, Kaito K, Tamura M, Nishida S, Kawakami K, Watanabe Y (2000) Small amount of low-residue diet with parenteral nutrition can prevent decreases in intestinal mucosal integrity. Ann Surg 231:112-118

17. Tyson JE, Kennedy KA (2005) Trophic feedings for parenterally fed infants. Cochrane Database Syst Rev 3:CD000504

18. Reeves PG, Nielsen FH, Fahey GC Jr (1993) AIN-93 purified diets for laboratory rodents: final report of the American Institute of Nutrition ad hoc writing committee on the reformulation of the AIN-76A rodent diet. J Nutr 123:1939-1951

19. Kuipers F, Havinga R, Bosschieter H, Toorop GP, Hindriks FR, Vonk RJ (1985) Enterohepatic circulation in the rat. Gastroenterology 88:403-411

20. Takeda N, Hasegawa S, Morita M, Matsunaga T (1993) Pica in rats is analogous to emesis: an animal model in emesis research. Pharmacol Biochem Behav 45:817-821

21. Bateman E, Bowen J, Stringer A, Mayo B, Plews E, Wignall A, Greenberg N, Schiffrin E, Keefe D (2013) Investigation of effect of nutritional drink on chemotherapy-induced mucosal injury and tumor growth in an established animal model. Nutrients 5:3948-3963
22. Blijlevens NM, Lutgens LC, Schattenberg AV, Donnelly JP (2004) Citrulline: a potentially simple quantitative marker of intestinal epithelial damage following myeloablative therapy. Bone Marrow Transplant 34:193-196

23. Crenn P, Vahedi K, Lavergne-Slove A, Cynober L, Matuchansky C, Messing B (2003) Plasma citrulline: a marker of enterocyte mass in villous atrophy-associated small bowel disease. Gastroenterology 124:1210-1219

24. Lutgens LC, Blijlevens NM, Deutz NE, Donnelly JP, Lambin P, de Pauw BE (2005) Monitoring myeloablative therapy-induced small bowel toxicity by serum citrulline concentration: a comparison with sugar permeability tests. Cancer 103:191-199

25. Lutgens LC, Deutz N, Granzier-Peeters M, Beets-Tan R, De Ruysscher D, Gueulette J, Cleutjens J, Berger M, Wouters B, von Meyenfeldt M, Lambin P (2004) Plasma citrulline concentration: a surrogate end point for radiation-induced mucosal atrophy of the small bowel. A feasibility study in 23 patients. Int J Radiat Oncol Biol Phys 60:275-285

26. van Vliet MJ, Tissing WJ, Rings EH, Koetse HA, Stellaard F, Kamps WA, de Bont ES (2009) Citrulline as a marker for chemotherapy induced mucosal barrier injury in pediatric patients. Pediatr Blood Cancer 53:1188-1194

27. Lukovac S, Los EL, Stellaard F, Rings EH, Verkade HJ (2008) Essential fatty acid deficiency in mice impairs lactose digestion. Am J Physiol Gastrointest Liver Physiol 295:G605-G613

28. van Eijk HM, Rooyakkers DR, Deutz NE (1993) Rapid routine determination of amino acids in plasma by high-performance liquid chromatography with a 2-3 microns Spherisorb ODS II column. J Chromatogr 620:143-148

29. Demacker PN, Beijers AM, van Daal H, Donnelly JP, Blijlevens NM, van den Ouweland JM (2009) Plasma citrulline measurement using UPLC tandem mass-spectrometry to determine small intestinal enterocyte pathology. J Chromatogr B Analyt Technol Biomed Life Sci 877:387-392

30. Taminiau JA, Gall DG, Hamilton JR (1980) Response of the rat small-intestine epithelium to methotrexate. Gut 21:486-492 